\title{
Haze pollution and urbanization promotion in China: How to understand their spatial interaction?
}

\section{Huachao Yang}

University of Jinan

\section{$\mathrm{He} \mathrm{Wu}$}

University of Jinan

Wei Liang ( $\square$ lw99@foxmail.com )

University of Jinan https://orcid.org/0000-0001-7179-9161

\section{Research Article}

Keywords: Urbanization, Haze pollution, 3SLS, GS3SLS, Spatial interaction

Posted Date: February 18th, 2022

DOI: https://doi.org/10.21203/rs.3.rs-664212/v2

License: (c) (i) This work is licensed under a Creative Commons Attribution 4.0 International License.

Read Full License 


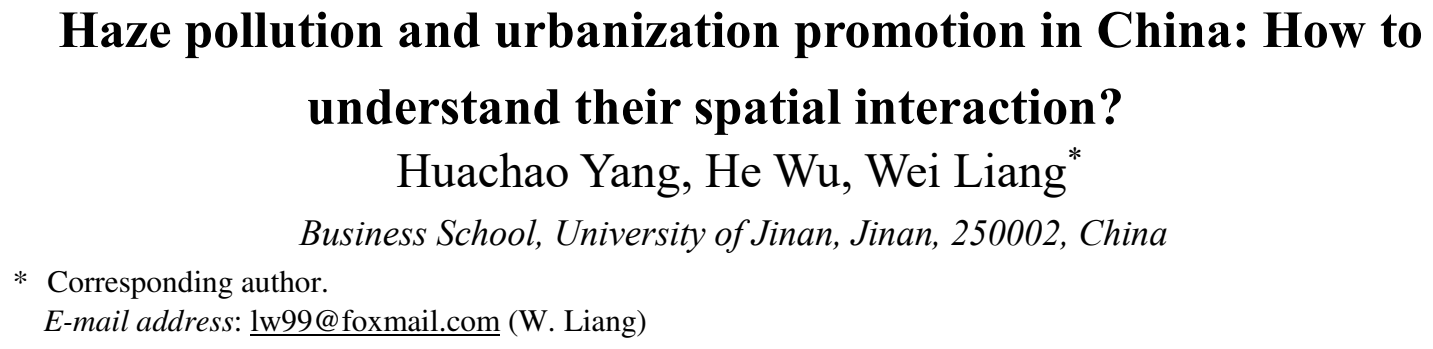

\begin{abstract}
Can promoting urbanization and controlling haze pollution result in a win-win situation? Based on panel data from 287 prefecture-level cities in China, this paper uses the threestage least-squares estimator method(3SLS) and generalized space three-stage leastsquares estimator method (GS3SLS) to study the spatial interaction between haze pollution and urbanization. The results show the following: (1) There is a spatial interaction between haze pollution and urbanization. On the whole, haze pollution and urbanization have a typical inverted U-shaped relationship. (2) Haze and urbanization show different relationships in different regions. The haze pollution in the area left of the Hu Line has a linear relationship with urbanization. (3) In addition to haze, urbanization also has a spatial spillover effect. When the haze pollution in the surrounding areas increases, the haze pollution in the area will also increase, but the level of urbanization will increase. When the level of urbanization in the surrounding areas increases, it will promote the level of urbanization in the local area and alleviate the haze pollution in the local area. (4) Tertiary industry, greening, FDI and precipitation can help alleviate haze pollution. FDI and the level of urbanization have a U-shaped relationship. In addition, industry, transportation, population density, economic level and market scale can promote regional urbanization.
\end{abstract}

Keywords Urbanization • Haze pollution • 3SLS • GS3SLS • Spatial interaction

\title{
1 Introduction
}

As a bad weather condition, haze pollution has been threatening people all over the world since the last century. The earliest record of the phenomenon is the "Great Smog of London" event in 1952. According to statistics, nearly 8000 people died of respiratory diseases caused by this haze incident. As far as China is concerned, the "severe haze event in central and eastern China" that occurred in 2013 was relatively similar to the event in London. At that time, the highest haze concentration in Shanghai reached $600 \mu \mathrm{g} / \mathrm{m}^{3}$ and that in Nanjing reached $943 \mu \mathrm{g} / \mathrm{m}^{3}$. Scholars have previously studied 129 cities in China and found that in 2015 alone, haze pollution caused 631230 premature deaths in 129 cities (G. Zhu et al., 2019). If the state does not introduce policy 
control, $2 \%$ of the GDP will be lost in 2030, and the estimated life loss will be 100 billion yuan (Y. Xie et al., 2019). Therefore, to control haze pollution, countries all over the world have carried out various aspects of exploration. For example, after the London incident, the London government encouraged the use of natural gas and promoted public transport. Germany has implemented the Clean Air Action Plan. However, haze pollution has many influencing factors, which make it difficult to control. For example, urbanization, energy intensity and natural factors affect haze pollution. Therefore, only by accurately understanding the interaction between haze pollution and its influencing factors can we better solve the problem of haze pollution.

Since the beginning of the 21st century, the popularity of computers has brought the world into the Information Age. Countries all over the world have made rapid developments. According to data released by the World Bank, the world's GDP in 2000 was 33.588 trillion US dollars, but by 2017, it had reached 80.951 trillion US dollars. China's achievements in infrastructure construction and economic construction have shocked the world, and the country's level of urbanization has been continuously improved. As shown in Fig.1, the proportion of China's urban population was only $36.22 \%$ in 2000 but had reached $59.58 \%$ by 2018 . The per capita electricity consumption increased from $1 \mathrm{MWh}$ in 2000 to $4.6 \mathrm{MWh}$ in 2017. Although China's progress is shocking, the environmental problems caused by this progress are increasingly frequent, especially haze pollution, which causes great harm to people's health and has attracted increasing attention in recent years. China still needs to make continuous progress in regard to urbanization, the social economy and so on. However, as a large energy user, maintaining good air quality has become China's responsibility. Therefore, improving air quality while promoting social development has become a problem we must think about. How can haze pollution be alleviated while promoting urbanization? What is the interaction between haze pollution and urbanization? Obviously, to realize the win-win situation of urbanization and haze pollution control, these questions must be answered first. However, haze pollution and urbanization are a pair of factors that can influence each other. Only by studying the interaction between haze and urbanization can we better describe the relationship between them.

Therefore, this paper uses the 3SLS and GS3SLS estimator methods to conduct a more in-depth study on the relationship between them. The first part of this paper is the introduction. The second part and the third part are a literature review and theoretical mechanism analysis. Model method and variables are the fourth part. The fifth part is empirical analysis. The sixth part is the robustness test. The seventh part is the conclusion and policy recommendations. 


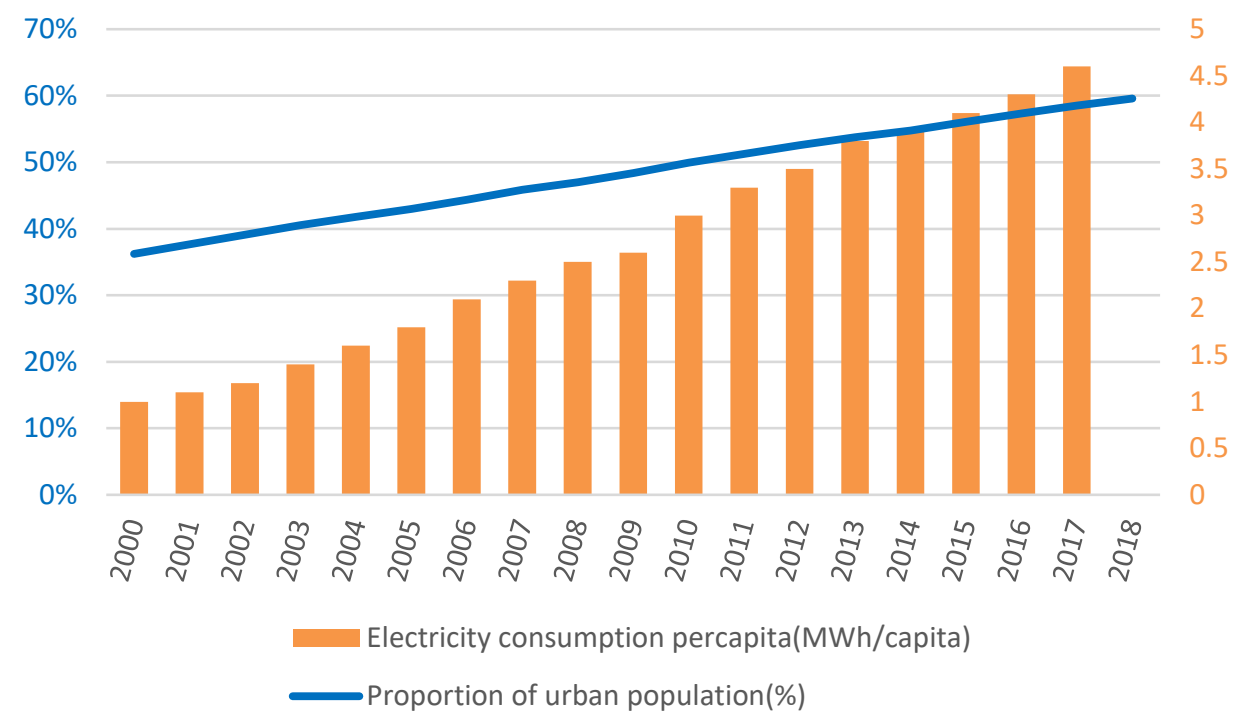

Fig.1 Proportion of urban population and electricity consumption per capita

\section{Literature review}

With the increasing frequency of haze pollution, the harm of this phenomenon to human health has received increasing attention. Chen et al. (2017) conducted a study on the impact of pollution in 2014 and found that if air quality meets national standards, then the number of people dying from health-related diseases can be reduced by approximately 168000 , and economic benefits of 33.2 billion yuan can be generated. Subsequently, Li et al. (2018) studied the harm of haze pollution on 62 cities in 2015 and found the negative impacts of haze pollution to be very significant. Among these impacts, approximately 125000 people died prematurely due to haze, the economic loss was approximately 57.06 billion yuan, and the per capita loss of these cities reached 1970 yuan.

By 2016, haze pollution was still causing huge losses in China, with 964000 deaths related to haze pollution and approximately 1.1 million related cases of chronic bronchitis and asthma. At the same time, such pollution caused economic losses of US $\$ 101.39$ billion, accounting for $0.91 \%$ of the national GDP in 2016 (Maji et al., 2018). The latest research also shows that from 2015 to 2017, the health loss caused by haze pollution reached 34.45 million yuan, and the economic loss reached 285.3 billion yuan. This research also shows that by 2017, haze pollution had decreased compared to previous years; however, this pollution level is still relatively serious (Fu et al., 2020). Haze pollution has a huge negative impact on human health and the social economy. Therefore, it is necessary to carry out a more in-depth study on haze pollution to achieve a win-win situation in regard to the governance of haze pollution and social development.

Haze pollution is related to many factors, which makes it difficult to control. Liu et al. (2019) found that industrial structure and roads can promote haze pollution. In a 
recent study, Zhang et al. (2019) studied 152 cities and found that emission intensity and energy intensity inhibited $\mathrm{PM}_{2.5}$ concentrations in 137 and 99 cities, respectively. Jiang et al. (2018) further studied the impact of socioeconomic factors on haze pollution and found that industrial activities have a greater impact on haze pollution. Social factors can explain $44 \%-48 \%$ of the changes in haze pollution. In addition to social factors, the impact of natural factors on haze pollution cannot be ignored (Yang et al., 2018). For example, Yang et al. (2017) found that temperature, humidity, wind speed and ground pressure all affect haze pollution. The research of Kliengchuay et al. (2021) also shows that haze is related to temperature and humidity. In addition, they also found that $\mathrm{PM}_{10}$ concentration is closely related to ozone concentration. de Arruda Moreira et al. (2021) by studying the changes of air quality before and after biomass burning events, they found that biomass burning has a negative impact on the air quality index associated with $\mathrm{PM}_{2.5}$. Zhao et al. (2019) found that the $\mathrm{PM}_{2.5}$ concentration will be relatively high in winter and relatively low in summer. Bai et al. (2020) research also supports the conclusion that the $\mathrm{PM}_{2.5}$ concentration is high in winter. In addition to social and natural factors, there are also some other factors that affect haze pollution. Shi et al. (2019) conducted a questionnaire survey and found that the psychological factors of individuals are also related to haze pollution. The psychological will of individuals regulates their behaviors towards haze pollution, thus affecting haze pollution. Therefore, it is very important to study the relationship between haze pollution and influencing factors more deeply and accurately.

Similar to haze pollution, urbanization also has many influencing factors. To promote urbanization more efficiently and realize the win-win situation of urbanization and haze control, it is also important to clarify the influence of many factors on urbanization. In terms of the economy, Bai et al. (2012) pointed out that in the long run, the expansion of built-up areas and per capita GDP are mutually causal; i.e., urbanization and economic growth have a positive feedback relationship. Economic development can affect not only the level of urbanization but also the regional differences in urbanization (Xu \& Hou, 2019). In addition, per capita GDP and the urban-rural income ratio also affect regional differences in urbanization (Lin et al., 2018). Ye et al. (2018) studied the impact of financial agglomeration, FDI, fixed asset investment and other factors on urbanization. They found that financial agglomeration can promote urbanization, but it has a smaller impact on the western region of China and a greater impact on the eastern and central regions. FDI and fixed asset investment can promote urbanization.

In addition to economic factors, government factors also affect urbanization. Zhou et al. (2017) used a logistic model to study land development and utilization and found that unlike foreign countries, urban land development in China is the result of cooperation and competition between local governments and enterprises. Only when 
enterprises and governments cooperate can land development achieve maximum benefits. In addition, public services and land finance are also factors affecting urbanization. Land finance has a significant role in promoting the process of urbanization, and the efficiency of public service supply significantly slows down the speed of urbanization marginalization (Lu et al., 2019). In addition to social factors, natural factors also have an impact on urbanization. Tian \& Wu (2015) found that roads and rivers have a significant impact on urbanization; i.e., urban areas are inversely proportional to the distance from the road and inversely U-shaped to the distance from the river. The latest research also shows that natural environmental pollution inhibits urbanization; in addition, with the rise of residents' health costs, the inhibition effect is increasingly stronger (Wu et al., 2020). Therefore, as an important factor affecting urbanization, it is very important to study the relationship between natural environmental pollution and urbanization in the process of urbanization.

With a deepening understanding of haze pollution hazards, research on haze and urbanization is gradually increasing. As early as 2014, Han et al. (2014) found that urbanization has a considerable impact on haze pollution. Fang et al. (2015) found that the air quality was significantly affected by urbanization. Subsequently, some scholars found that urbanization leads to an increase in the number of immigrants, which leads to an increase in traffic emissions in urban areas, thereby aggravating haze pollution (Shen et al., 2017). However, Liu et al. (2018) found that wetlands in areas with high levels of urbanization are conducive to alleviating haze pollution; therefore, retaining wetlands in the process of urbanization can moderately alleviate haze pollution. Since then, people have conducted more in-depth research on urbanization and haze pollution. For example, many studies have found inverted U-shaped and inverted N-shaped relationships between urbanization and haze pollution(Wu et al., 2018; Dong et al., 2020; X. Wang et al., 2018; W. Xie et al., 2019; Xu et al., 2019). Of course, the opposite view also exists. W. Zhu et al. (2019) divided urbanization into economic, land and population urbanization and found that there is no inverted U-shaped or inverted Nshaped relationship between economic urbanization and haze pollution but only a linear relationship. Population urbanization can alleviate haze pollution, while land urbanization has no significant impact on haze pollution. Some studies have considered the influence of spatial lag. Du et al. (2018) showed that when the urbanization of surrounding areas increases, the urbanization of this region will also increase. Du et al. (2019) pointed out that the spatial dependence of $\mathrm{PM}_{2.5}$ is generally within the range of $200 \mathrm{~km}$. Local and surrounding economic urbanization have a significant impact on the $\mathrm{PM}_{2.5}$ concentration, and population urbanization has no significant effect on the $\mathrm{PM}_{2.5}$ concentration. In addition to using China's data to study China's urbanization and haze pollution, some scholars also use the data of other countries in the world. N. Wang et al. (2018) found an inverted U-shaped relationship between urbanization and haze 
pollution based on data from G20 countries. Wang et al. (2020) divided 190 countries into four subpanels according to the level of national income and found that the impact of urbanization on haze pollution is significantly different between income-based subpanels. This shows that each country should formulate appropriate haze control strategies according to its own urbanization level.

In summary, most of the current studies on the relationship between haze pollution and urbanization only consider one-way impacts, while some scholars have pointed out that they can cause and effect each other (Zhao et al., 2018). That is, haze pollution and urbanization are a pair of variables that can influence each other. Only by studying the interaction between these two factors can we describe the relationship between haze pollution and urbanization more accurately. The existing research has not been involved in such a description up to this point. Therefore, we use the 3SLS and GS3SLS methods to study how haze and urbanization interact in space. Compared to previous studies, this study considers the interaction between haze pollution and urbanization. At the same time, the spatial spillover effect between the two factors is considered to make the result more convincing. It is hoped that this study can supplement the theory of the interaction between haze pollution and urbanization. At the same time, it provides a reference for haze pollution control and urbanization development.

\section{Theoretical mechanism analysis}

\subsection{The effect of urbanization on haze pollution}

The measurement of urbanization level involves many indicators, such as population and land. Some of these factors can achieve sustainable development, while others will lead to environmental degradation. The process of urbanization is accompanied by the optimization of the industrial structure. At present, China is mainly focused on secondary industry, which requires much energy use and is often accompanied by high levels of pollution. In the process of urbanization, this will change gradually, and the industrial structure will gradually be dominated by the third industry with low pollution. Therefore, in the process of urbanization, haze pollution is often affected by the "structural effect". In addition, to beautify urban areas and meet people's needs in the process of urbanization, many green spaces and parks are built in cities. According to people's subjective feelings, the air quality in places with more green vegetation is better. Lu et al. (2017); Qin et al. (2020) also believe that greening can help alleviate haze. In the process of urbanization, the urban population increases, so the traffic pressure increases. To reduce traffic pressure, existing roads will be optimized or new roads will be built. Better or longer traffic roads often lead to an increase in vehicle flow, which will impose a burden on the environment and aggravate haze pollution.

Urbanization brings about further development to the region. It is a potential 
market for investors, and such regions will further open to the outside world to attract foreign investment. To attract foreign investment, regions often lower the environmental standards to attract foreign investment, thus causing environmental pollution (Zeng \& Shen, 2019). This is called the pollution paradise hypothesis. Some scholars have different views, and they think that FDI does not aggravate China's haze pollution (Zhou et al., 2019). In addition, studies have shown that China's urbanization has the characteristics of spatial agglomeration (Liu et al., 2020b). The advantage of spatial agglomeration is that it can promote technological exchange and competition between cities and towns, thus promoting the development of cities and towns. However, the agglomeration of urbanization leads to an increase in regional energy consumption; therefore, urbanization may also affect haze pollution through the agglomeration effect.

\subsection{The effect of haze pollution on urbanization}

First, in periods of relatively serious haze, the government will issue a series of environmental protection laws and regulations, adjust the industrial structure in a short period of time, and strictly restrict some secondary industrial sectors that are vulnerable to pollution. This will strictly increase the cost of these industries, and many enterprises will shut down, leading to a large amount of worker unemployment. Urbanization thus includes the urbanization of both land and personnel. When workers are unemployed, this will have a greater impact on urbanization. Second, in addition to restricting highpollution industries, foreign-funded enterprises may also be subject to strict restrictions, prompting foreign-funded enterprises to adopt environmental protection technologies to break the pollution paradise hypothesis. To promote urbanization, the government will build roads to increase the number of vehicles, which will easily lead to haze pollution and traffic congestion. To solve this problem, the government will further carry out road construction to further promote urbanization.

Gan et al. (2021) shows that haze is closely related to the economy. Economy also has a great influence on urbanization. When regional economic development is better, it is more conducive to regional urbanization. In addition, studies have shown that haze pollution has an immigration effect, with people being more willing to go to cities with good air quality and low levels of haze pollution (Li \& Zhang, 2019). This increases the population and the labor force in the immigration area, while the labor force in the area with more serious haze pollution decreases. This change in the labor force will have a significant impact on the construction of the city. Although the labor force may be reduced in areas with heavy haze, heavy pollution levels often cause people's attention to health to increase and stimulate people's demand for green and healthy products, which expands the local market scale, helps attract enterprises to enter and promotes local development. 


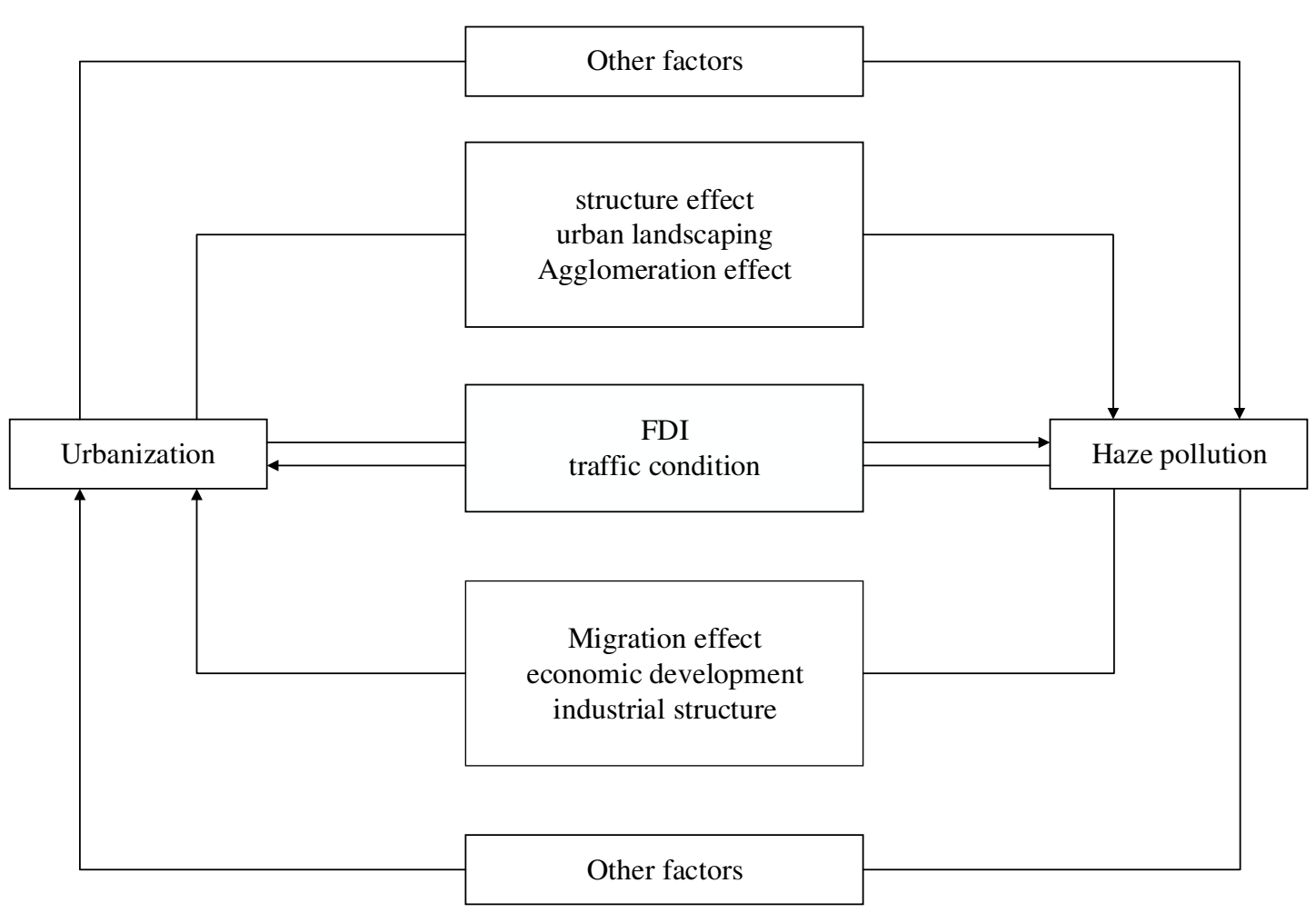

Fig.2 Interaction mechanism

\section{Model method and variables}

\subsection{Model method}

According to the analysis above, haze and urbanization may have mutual influence. If we only use a single equation model to estimate and study the influence of one direction, the result is not accurate. Therefore, based on panel data from 287 prefecturelevel cities from 2000 to 2017, this paper uses 3SLS and GS3SLS to explore whether haze pollution and urbanization can interact.

3SLS is a complete information estimation method. First, it estimates each equation by 2SLS, and then it estimates the covariance matrix of the disturbance term of the whole system. Finally, it estimates the GLS of the whole system. GS3SLS introduces spatial factors on the basis of 3SLS and introduces the spatial lag term and spatial weight matrix into the simultaneous equation model.

The simultaneous equation model between haze pollution and urbanization is established as follows:

$$
\begin{gathered}
\operatorname{lnpm}_{i t}=\alpha_{0}+\alpha_{1} \operatorname{lnurb}_{i t}+\alpha_{2} \operatorname{lnurb}_{i t}+\sum_{\alpha=3}^{n} \alpha_{i} X_{i t}+\mu_{i t} \\
\operatorname{lnurb}_{i t}=\gamma_{0}+\gamma_{1} \operatorname{lnpm}_{i t}+\sum_{i=2}^{n} \gamma_{i} Y_{i t}+\varphi_{i t}
\end{gathered}
$$

where $\operatorname{lnpm}_{i t}$ is the logarithm of $\mathrm{PM}_{2.5}$ concentration in year $t$ of area $i$, while lnurb $b_{\text {it }}$ and lnurb $2_{\text {it }}$ are the logarithm of urbanization and urbanization square of area $i$ in year $t$, respectively. $\mathrm{X}_{\mathrm{it}}$ and $\mathrm{Y}_{\mathrm{it}}$ are control variables of the haze pollution equation and 
urbanization equation, respectively; $\alpha_{0}$ and $\gamma_{0}$ are constant terms of the haze pollution equation and urbanization equation, respectively; and $\mu_{i t}$ and $\varphi_{i t}$ are disturbance terms. By introducing the spatial lag term and the spatial weight matrix into model 1 and model 2 , the spatial simultaneous equation model constructed in this paper can be obtained as follows:

$$
\begin{gathered}
\operatorname{lnpm}_{i t}=\alpha_{0}+\rho_{1} w_{i j} \operatorname{lnpm}_{i t}+\alpha_{1} \operatorname{lnurb}_{i t}+\alpha_{2} \operatorname{lnurb}_{i t}+\sum_{\alpha=3}^{n} \alpha_{i} X_{i t}+\mu_{i t} \\
\operatorname{lnurb}_{i t}=\gamma_{0}+\rho_{3} w_{i j} \operatorname{lnurb}_{i t}+\gamma_{1} \operatorname{lnpm}_{i t}+\sum_{i=2}^{n} \gamma_{i} Y_{i t}+\varphi_{i t}
\end{gathered}
$$

where $w_{i j}$ is the spatial panel weight matrix. To be more comprehensive, this paper comprehensively considers the economic factors and geographical distance factors and constructs the geographical weight matrix of the panel economy with reference to S. Wang (2013); that is, it is the reciprocal of the absolute value of the product of the difference between the per capita GDP of two cities and the linear distance. The remaining variables are the same as previously mentioned.

\subsection{Variable selection}

\subsubsection{Selection of endogenous variables}

This paper studies the interaction between urbanization and haze pollution. The model includes the urbanization equation and haze pollution equation, and each equation has an explained variable. The selection of the explained variables for each equation is described below.

First, we discuss the choice of dependent variable in the haze pollution equation. For the haze pollution equation, we choose the most mainstream and direct annual average $\mathrm{PM}_{2.5}$ concentration in prefecture-level cities as the dependent variable. This is also the mainstream way for scholars to measure haze pollution. This is expressed in lnpm.

Next, we discuss the choice of dependent variable in the urbanization equation. Urbanization is a comprehensive index that includes the urbanization of land and the increase in built-up areas. It also includes the urbanization of personnel and so on. Therefore, to characterize urbanization more comprehensively, we refer to the articles by Cai \& Lv (2018); Li \& Zhang (2011); F. Wang et al. (2013) and other scholars. After standardizing the unit built-up area and the number of on-the-job employees per unit area of each city, we use the entropy weight method (EWM) to represent the urbanization level. We calculate the information entropy of each data point as $E_{J}=$ $-\frac{1}{\ln n} \sum_{i=1}^{n} p_{i j} \ln p_{i j}$, where $p_{i j}=x_{i j} / \sum_{i=1}^{n} x_{i j}$. After obtaining the information entropy for $\mathrm{E}_{1}, \mathrm{E}_{2}, \ldots, \mathrm{E}_{\mathrm{k}}$, the weight of each index is determined as $w_{i}=\left(1-E_{i}\right) /\left(k-\sum E_{i}\right)$. Urbanization $_{\text {it }}=\sum_{1}^{n} w_{i} R_{i j}$, where $R_{i j}$ is the normalized value. In this paper, the weight of the unit built-up area and number of on-the-job workers per unit area are 0.47 and 0.53 , respectively. Compared to a single indicator, this process can reflect urbanization 
more comprehensively. At the same time, this paper introduces the square term of urbanization. Urbanization is represented by lnurb, and the quadratic term of urbanization is represented by lnurb2.

\subsubsection{Selection of control variables}

Next, we discuss the selection of control variables for the haze pollution equation. Haze pollution has many influencing factors, including social factors and natural factors. To be more comprehensive and social control variables, we choose the proportion of three industries (lnsc), greening degree (lngre), FDI (lnfdi) and traffic condition (lntra). For the control variable related to natural factors, we choose precipitation ( prec). The proportion of the tertiary industry in GDP is used to express the proportion of the tertiary industry. The per capita green area of each area is used to indicate the degree of greening. The real amount of FDI per capita in the region is used to represent FDI. Because the administrative areas of different prefecture-level cities are different, we take the unit road area to measure the traffic situation. The precipitation is expressed by the annual average precipitation of each region. The original annual precipitation data in each region are from the European Center for Medium Range Weather Forecasts. The annual average precipitation of each region was extracted by ArcGIS software.

Finally, we discuss the choice of control variables in the urbanization equation. For the urbanization equation, we choose the proportion of secondary industry (lnec), FDI (lnfdi), the FDI square term (lnfdi2), population density (lnpopu), traffic condition (lntra), market scale (lnmar) and economic level (lnecon) as control variables. The proportion of the output value of the secondary industry in GDP is used to express the proportion of the secondary industry. The population density is represented by the population density of each region. Retail sales of consumer goods are used to represent market scale. The economic level is expressed by the annual average nighttime light intensity of each region. Compared to the GDP, the nighttime light data come from satellite data, which reflects the economic level more objectively. Nighttime light intensity refers to the extraction method of Cao Ziyang, Liang Li and other scholars (Cao et al., 2015; Chai et al., 2015; Liang et al., 2020; Liu et al., 2012). The original data are from the NOAA National Environmental Information Center. After saturation correction, continuity correction and other processes, ArcGIS software is used to extract the average nighttime light intensity of cities at different levels from 2000 to 2017 to represent the economic level of each region.

\subsubsection{Data sources}

The $\mathrm{PM}_{2.5}$ concentration data are from the Atmospheric Composition Analysis Group at Dalhousie University ${ }^{1}$. The annual mean $\mathrm{PM}_{2.5}$ concentrations were extracted

1 http://fizz.phys.dal.ca/ atmos/martin/?page_id =140 
350

351

352

353

354

355

356

357

358

359

360

by ArcGIS software. Precipitation data are from the European Center for Medium Range Weather Forecasts ${ }^{2}$. The nighttime light intensity data are from the NOAA National Environmental Information Center ${ }^{3}$. The precipitation and nighttime light intensity were also extracted by ArcGIS software. Other control variables are from the 2001-2018 China Urban Statistical Yearbook, as well as the statistical yearbook of local cities and their statistical annual reports. Among these sources, the economic data are based on the year 2000, excluding the price factor; in addition, the data related to foreign exchange are calculated according to the annual average exchange rate. The data is logarithmically processed. Because the values of precipitation data are small, the logarithm is not taken. The descriptive statistics of the data are shown in Table 1.

Table 1 Descriptive statistics of data

\begin{tabular}{ccccc}
\hline variable & $\max$ & $\min$ & mean & sd \\
\hline lnpm & 4.6822 & 1.141 & 3.6267 & 0.5037 \\
lnurb & 4.3876 & -4.0633 & 1.1613 & 1.0091 \\
Insc & 4.4854 & 2.1401 & 3.6112 & 0.2605 \\
Intra & 6.4693 & -3.9243 & 3.0533 & 1.2358 \\
Ingre & 6.4996 & -2.7901 & 1.9284 & 1.1701 \\
lnec & 4.525 & 2.0857 & 3.8599 & 0.2893 \\
Infdi & 11.2758 & -3.1492 & 5.1487 & 1.912 \\
prec & 0.0948 & 0.003 & 0.0371 & 0.0184 \\
Inpopu & 9.3557 & 1.5476 & 5.7053 & 0.9248 \\
Inmar & 18.5888 & 5.4723 & 14.6545 & 1.2569 \\
lnecon & 4.4545 & -2.9318 & 0.8908 & 1.3459 \\
\hline
\end{tabular}

361

\section{Empirical analysis}

\subsection{Spatial autocorrelation analysis}

\subsubsection{Global spatial autocorrelation analysis}

First, the spatial autocorrelation between haze pollution and urbanization is verified. We will explore by calculating the global Moran's I index. The formula is as follows:

$$
I=\frac{n \sum_{i=1}^{n} \sum_{j=1}^{n} w_{i j}\left(x_{i}-\bar{x}\right)\left(x_{j}-\bar{x}\right)}{n \sum_{i=1}^{n} \sum_{j=1}^{n} w_{i j} \sum_{i=1}^{n}\left(x_{i}-\bar{x}\right)^{2}}
$$

where $x_{i}$ and $x_{j}$ are the corresponding variables of haze pollution or urbanization in the two regions, respectively, and $\mathrm{w}_{\mathrm{ij}}$ is the spatial weight matrix. Here, we use the standardized spatial adjacency weight matrix. The results of the global spatial

\footnotetext{
2 https://cds.climate.copernicus.eu/cdsapp\#!/dataset/reanalysis-era5-single-levels-monthlymeans?tab=overview

3 https://ngdc.noaa.gov/eog/download.html
} 
371 autocorrelation test are shown in Table 2.

372 Table 2 Global spatial autocorrelation test results

\begin{tabular}{c|ccc|ccc}
\hline \multirow{2}{*}{ year } & \multicolumn{3}{c|}{ lnpm } & & \multicolumn{3}{c}{ lnurb } \\
\cline { 2 - 7 } & Moran's I & $\mathrm{z}$ & $\mathrm{p}$-value* & Moran's I & $\mathrm{z}$ & p-value* \\
\hline 2000 & 0.813 & 20.432 & 0.000 & 0.274 & 6.963 & 0.000 \\
2001 & 0.812 & 20.456 & 0.000 & 0.268 & 6.791 & 0.000 \\
2002 & 0.793 & 19.963 & 0.000 & 0.285 & 7.222 & 0.000 \\
2003 & 0.774 & 19.477 & 0.000 & 0.291 & 7.387 & 0.000 \\
2004 & 0.781 & 19.732 & 0.000 & 0.295 & 7.48 & 0.000 \\
2005 & 0.786 & 19.835 & 0.000 & 0.287 & 7.277 & 0.000 \\
2006 & 0.778 & 19.610 & 0.000 & 0.279 & 7.093 & 0.000 \\
2007 & 0.796 & 20.066 & 0.000 & 0.299 & 7.577 & 0.000 \\
2008 & 0.767 & 19.323 & 0.000 & 0.301 & 7.632 & 0.000 \\
2009 & 0.727 & 18.380 & 0.000 & 0.31 & 7.863 & 0.000 \\
2010 & 0.751 & 18.958 & 0.000 & 0.362 & 9.142 & 0.000 \\
2011 & 0.774 & 19.515 & 0.000 & 0.32 & 8.116 & 0.000 \\
2012 & 0.780 & 19.650 & 0.000 & 0.338 & 8.559 & 0.000 \\
2013 & 0.768 & 19.365 & 0.000 & 0.358 & 9.063 & 0.000 \\
2014 & 0.730 & 18.419 & 0.000 & 0.346 & 8.749 & 0.000 \\
2015 & 0.752 & 18.946 & 0.000 & 0.375 & 9.468 & 0.000 \\
2016 & 0.773 & 19.443 & 0.000 & 0.373 & 9.426 & 0.000 \\
2017 & 0.748 & 18.845 & 0.000 & 0.386 & 9.766 & 0.000 \\
\hline
\end{tabular}

373

374

375

Both haze pollution and urbanization have high spatial autocorrelation at the significance level of $1 \%$. The spatial autocorrelation of urbanization is weaker than that of haze pollution, but the spatial autocorrelation of urbanization increases with time.

\subsubsection{Local spatial autocorrelation test}

Local spatial autocorrelation is investigated by drawing a Moran scatter plot. Due to space limitations, we have only drawn Moran scatter plots of urbanization and haze pollution in 2000, 2006, 2012, and 2017, as shown in Fig.3 and Fig.4. The Moran scatter diagram of urbanization and haze pollution shows that urbanization and haze pollution present spatial agglomeration characteristics. 
2000

2006
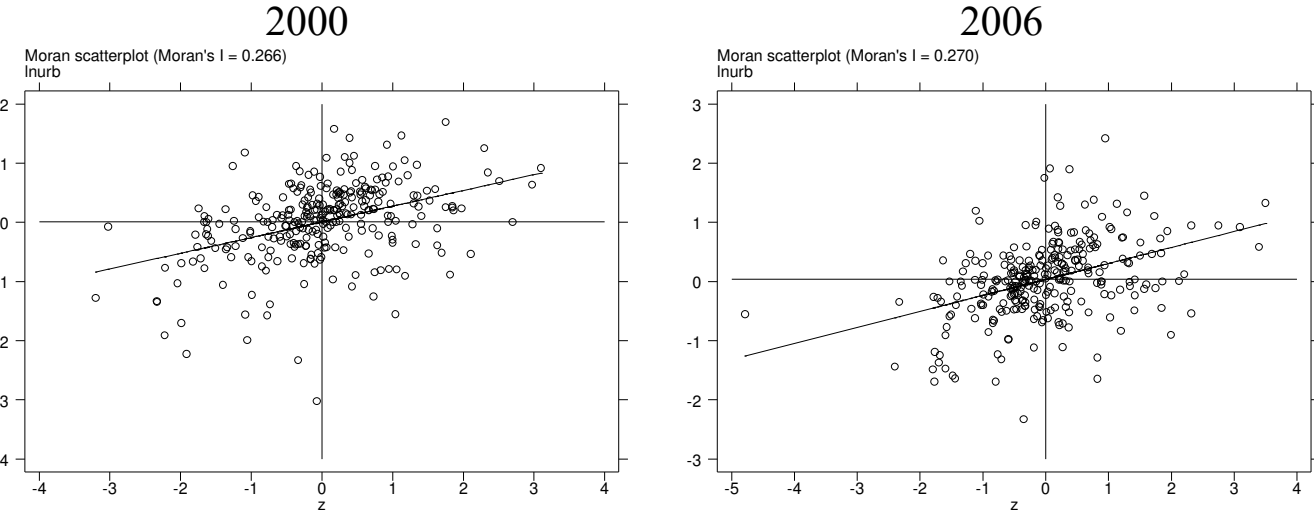

2012

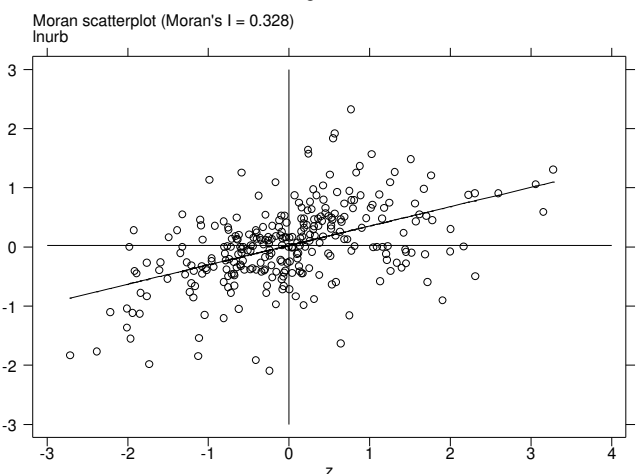

2017

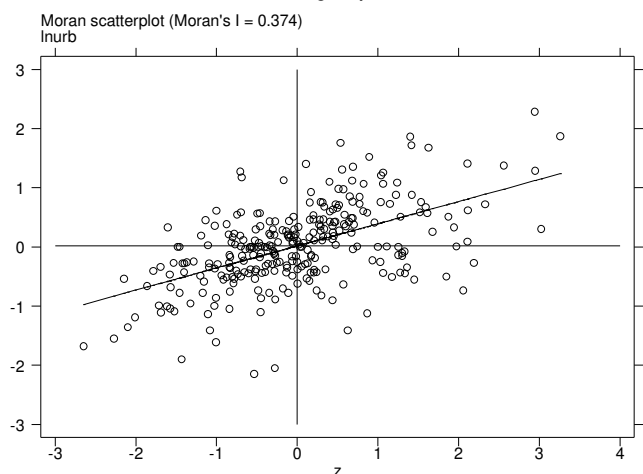

383

Fig.3 scatter plot of urbanization

2000

Moran scatterplot (Moran's I = 0.788)
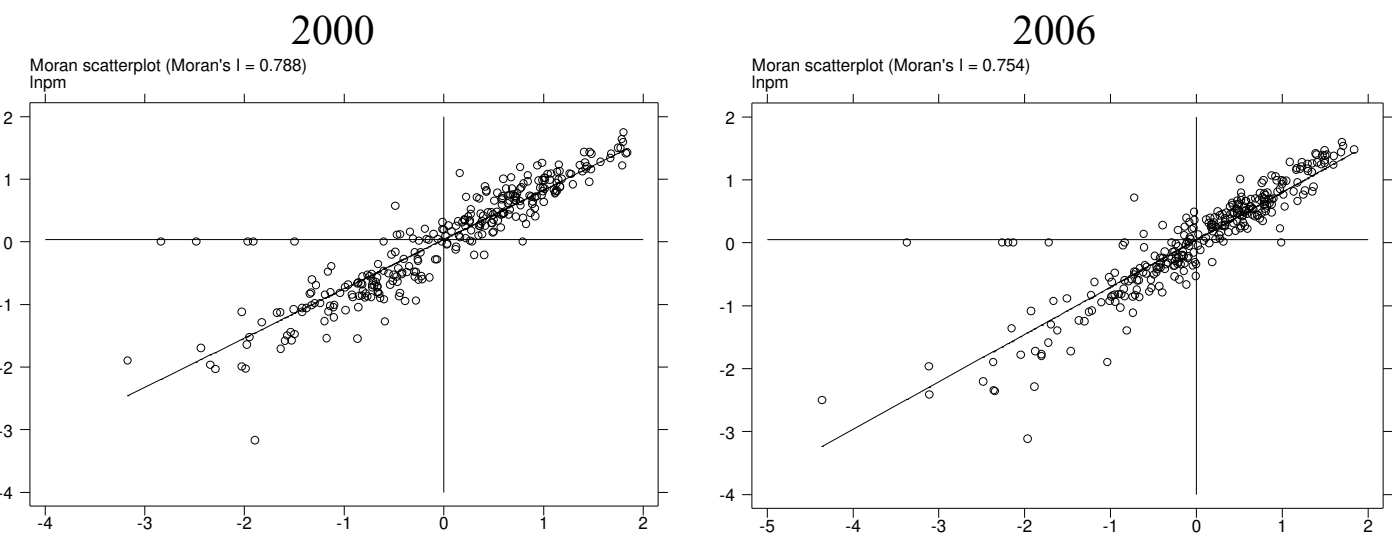

2012

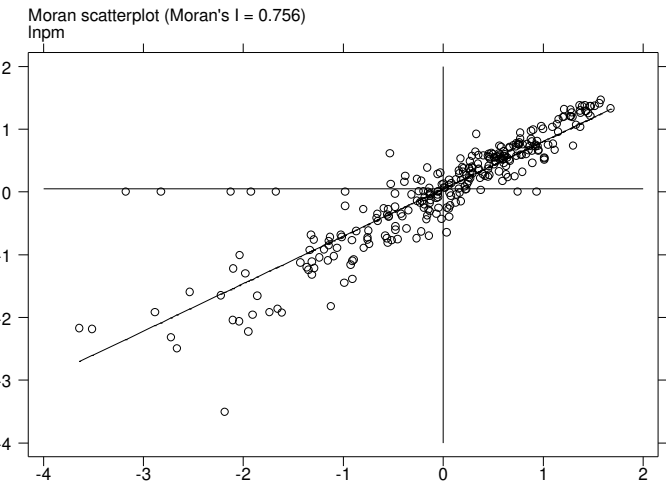

2017

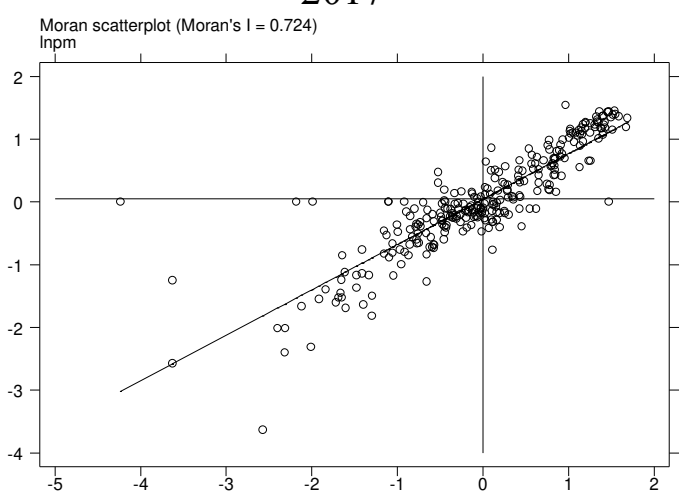

Fig.4 scatter plot of haze 


\subsection{Empirical results}

386

To remove the correlation of random disturbance terms between equations, 3SLS

387 is used. At the same time, considering the spatial spillover effect of endogenous

388 variables, this paper uses GS3SLS to make estimates. The estimation results of the two

389 methods are shown in Table 3.

390 Table 3 Estimation results of 3SLS and GS3SLS

\begin{tabular}{|c|c|c|c|c|}
\hline \multirow{2}{*}{ variable } & \multicolumn{2}{|c|}{ lnpm } & \multicolumn{2}{|c|}{$\operatorname{lnurb}$} \\
\hline & 3SLS(equation 1) & GS3SLS(equation 3) & 3SLS(equation 2) & GS3SLS(equation 4) \\
\hline lnpm & & & $\begin{array}{c}-0.494 * * * \\
(-9.67)\end{array}$ & $\begin{array}{c}-1.062 * * * \\
(-15.71)\end{array}$ \\
\hline lnurb & $\begin{array}{c}0.379 * * * \\
(12.21)\end{array}$ & $\begin{array}{c}0.245^{* * *} \\
(10.45)\end{array}$ & & \\
\hline lnurb2 & $\begin{array}{c}-0.078 * * * \\
(-10.77)\end{array}$ & $\begin{array}{c}-0.067 * * * \\
(-12.45)\end{array}$ & & \\
\hline$W^{*} \operatorname{lnpm}$ & & $\begin{array}{c}0.718 * * * \\
(29.97)\end{array}$ & & $\begin{array}{c}0.763 * * * \\
(10.91)\end{array}$ \\
\hline$W^{*} \operatorname{lnurb}$ & & $\begin{array}{c}-0.164 * * * \\
(-10.78)\end{array}$ & & $\begin{array}{c}0.139 * * * \\
(4.86)\end{array}$ \\
\hline $\operatorname{lnsc}$ & $\begin{array}{c}-0.128 * * * \\
(-4.65)\end{array}$ & $\begin{array}{c}-0.064 * * * \\
(-2.93)\end{array}$ & & \\
\hline lnec & & & $\begin{array}{c}0.075^{* *} \\
(2.05)\end{array}$ & $\begin{array}{c}0.164 * * * \\
(4.20)\end{array}$ \\
\hline lngre & $\begin{array}{c}-0.066^{* * * *} \\
(-9.24)\end{array}$ & $\begin{array}{c}-0.036 * * * \\
(-6.22)\end{array}$ & & \\
\hline $\ln f d i$ & $\begin{array}{c}-0.038 * * * \\
(-7.88)\end{array}$ & $\begin{array}{c}-0.008 * * \\
(-2.02)\end{array}$ & $\begin{array}{c}-0.034 * \\
(-1.94)\end{array}$ & $\begin{array}{c}-0.075 * * * \\
(-4.09)\end{array}$ \\
\hline $\operatorname{lnfdi2}$ & & & $\begin{array}{c}0.004 * * \\
(2.10)\end{array}$ & $\begin{array}{c}0.006^{* * * *} \\
(2.97)\end{array}$ \\
\hline lntra & $\begin{array}{c}0.168 * * * \\
(17.05)\end{array}$ & $\begin{array}{c}0.144 * * * \\
(18.80)\end{array}$ & $\begin{array}{c}0.045^{* * *} \\
(2.68)\end{array}$ & $\begin{array}{c}0.045^{* * *} \\
(2.65)\end{array}$ \\
\hline lnecon & & & $\begin{array}{c}0.282 * * * \\
(19.52)\end{array}$ & $\begin{array}{c}0.298 * * * \\
(20.28)\end{array}$ \\
\hline Іпрори & & & $\begin{array}{c}0.358 * * * \\
(16.79)\end{array}$ & $\begin{array}{c}0.330 * * * \\
(15.19)\end{array}$ \\
\hline lnmar & & & $\begin{array}{c}0.171^{* * * *} \\
(16.14)\end{array}$ & $\begin{array}{c}0.170^{* * *} \\
(14.86)\end{array}$ \\
\hline prec & $\begin{array}{c}-6.640 * * * \\
(-17.63)\end{array}$ & $\begin{array}{c}-3.473 * * * \\
(-11.26)\end{array}$ & & \\
\hline _cons & $\begin{array}{c}3.887 * * * \\
(39.25)\end{array}$ & $\begin{array}{c}1.117 * * * \\
(9.55)\end{array}$ & $\begin{array}{c}-2.218 * * * \\
(-10.10)\end{array}$ & $\begin{array}{c}-3.100 * * * \\
(-10.81)\end{array}$ \\
\hline
\end{tabular}

$\mathrm{t}$ statistics in parentheses 
$* \mathrm{p}<0.1, * * \mathrm{p}<0.05, * * * \mathrm{p}<0.01$

\subsubsection{Analysis results of haze pollution equation}

From model 1 and model 3 in Table 3, it can be seen that whether the GS3SLS method considering spatial factors or the 3SLS method without considering spatial factors is adopted, the coefficient corresponding to the first term of urbanization (lnurb) is positive and that of the quadratic term (lnurb2) is negative. The results show that there is an inverted U-shaped relationship between urbanization and haze pollution. Without considering the spatial factors, the turning point is the urbanization rate of $11.35 \%$. When the spatial factors are considered, the inflection point becomes $6.22 \%$, which indicates that the speed of reaching the inflection point increases after considering the spatial factors. Therefore, considering the factors of space, regional cooperation and urbanization will become a relatively fast way to alleviate haze pollution.

From the spatial lag term in model 3, the spatial lag term of haze pollution ( $\left.W^{*} \operatorname{lnpm}\right)$ is positive and that of urbanization $\left(W^{*} \operatorname{lnurb}\right)$ is positive. The results show that the haze in this region will increase with the increase in haze in surrounding areas. When the urbanization level of the surrounding areas increases, the local haze pollution will be alleviated. According to the above spatial agglomeration analysis and the spatial lag term of urbanization in the empirical results, urbanization has a certain spatial spillover effect and has the characteristics of high agglomeration or low agglomeration. After the urbanization level of the surrounding areas is improved, the urbanization level of the region will also develop. For other control variables, increasing the proportion of the tertiary industry (lnsc) and the greening degree (lngre) can significantly alleviate haze pollution. Increasing FDI (lnfdi) can also alleviate haze pollution. The possible reason for these outcomes is that when foreign investment increases, enterprises have more capital with which to upgrade their equipment and technology to adapt to the environment and may also introduce foreign advanced technology to reduce pollution. Therefore, in China as a whole, the pollution paradise hypothesis is not tenable. Traffic conditions (lntra) significantly increase haze pollution. When traffic development increases, the level of car driving and exhaust emissions increases, thus increasing the severity of haze pollution. For natural factors, at the significance level of $1 \%$, both model 1 and model 3 show that precipitation (prec) can significantly reduce haze pollution. The main component of haze is $\mathrm{PM}_{2.5}$ floating in the air. When the precipitation increases, the $\mathrm{PM}_{2.5}$ in the air can be wrapped in rainwater to achieve the air purification effect.

\subsubsection{Analysis results of urbanization equation}

In both model 2 and model 4, haze pollution (lnpm) hinders urbanization (lnurb) 
at the significance level of $1 \%$, and the effect of hindrance is more obvious when considering spatial factors. Therefore, the impact of haze pollution on urbanization is underestimated in the traditional econometric model. The coefficient of the spatial lag term of haze pollution $\left(W^{*} \ln p m\right)$ in model 4 is 0.763 . This result shows that the urbanization of this region will increase with the aggravation of haze in surrounding areas. A possible reason for this result is that both residents and developers tend to choose areas with better environments; therefore, when the haze in this area is lighter, it is more likely to be favored by immigrants and developers. Similarly, the coefficient of the spatial lag of urbanization ( $W^{*} \ln u r b$ ) in model 4 is 0.139 at the significance level of $1 \%$, which indicates that when the urbanization level of surrounding areas is relatively high, it also has a certain driving effect on the urbanization of the region. A possible reason for this outcome is that when the urbanization level of the surrounding areas is relatively high, the region will also use the market and economy of the surrounding areas to construct the urbanization of the region.

For the control variables, at the significance level of $1 \%$, increasing the proportion of secondary industry $(\operatorname{lnec})$ can increase local urbanization. The secondary industry mainly consists of heavy industry, which needs much manpower and can thus directly promote both local employment and urbanization. The corresponding coefficient of $\mathrm{FDI}(\ln f d i)$ is -0.075 , and the quadratic coefficient of $\mathrm{FDI}(\ln f d i 2)$ is 0.006 , which are significant at the significance level of $1 \%$. Thus, the results show that FDI and urbanization have a positive U-shaped relationship. With the increase in FDI, the level of urbanization will first decrease and then increase. The inflection point is that the per capita FDI is 518.01 yuan. When the per capita FDI exceeds 518.01 yuan, urbanization will increase with the increase in per capita FDI. Traffic conditions (lntra), economic level (lnecon), population density (lnpopu) and market scale (lnmar) all promote urbanization at the significance level of $1 \%$. When traffic conditions are relatively developed, it is easy to communicate with the outside world and transport goods. The higher the economic level is, the more money will be spent on construction, thus promoting urbanization. When the population density is greater, it means that there are more labor resources; as is often the case, the more abundant the labor resources, the lower the labor cost is, which is favored by enterprises and thus promotes urbanization. When the whole region has a large market scale, residents will have a higher willingness to consume, and then the local market will more easily attract foreign enterprises to enter and promote urbanization.

\subsection{Analysis of regional heterogeneity}

In 1935, Chinese geographer Hu Huanyong drew a line on a map of China with Heihe city as the starting point and Tengchong County as the ending point, which was called the $\mathrm{Hu}$ Line. According to the census, the area on the right side of the $\mathrm{Hu}$ Line 
465

466

467

468

469

470

471

472

473

474

only accounts for $43.8 \%$ of the total area of China, while the proportion of the population located on that side is as high as $94.1 \%$. Both the economy and urbanization levels in the eastern region far outperform those for the western region of the $\mathrm{Hu}$ Line. For further study, we divide the study area into eastern and western regions of the $\mathrm{Hu}$ Line to study the regional consistency. We use ArcGIS software to determine the longitude and latitude coordinates of the starting point and end point of the $\mathrm{Hu}$ Line, and we divide the line into left-side and right-side areas. The area through which the $\mathrm{Hu}$ Line passes is allocated according to the area size on both sides. The division results of the Hu Line in China are shown in Fig.5. The empirical results of 287 prefecturelevel cities are shown in Table 4.
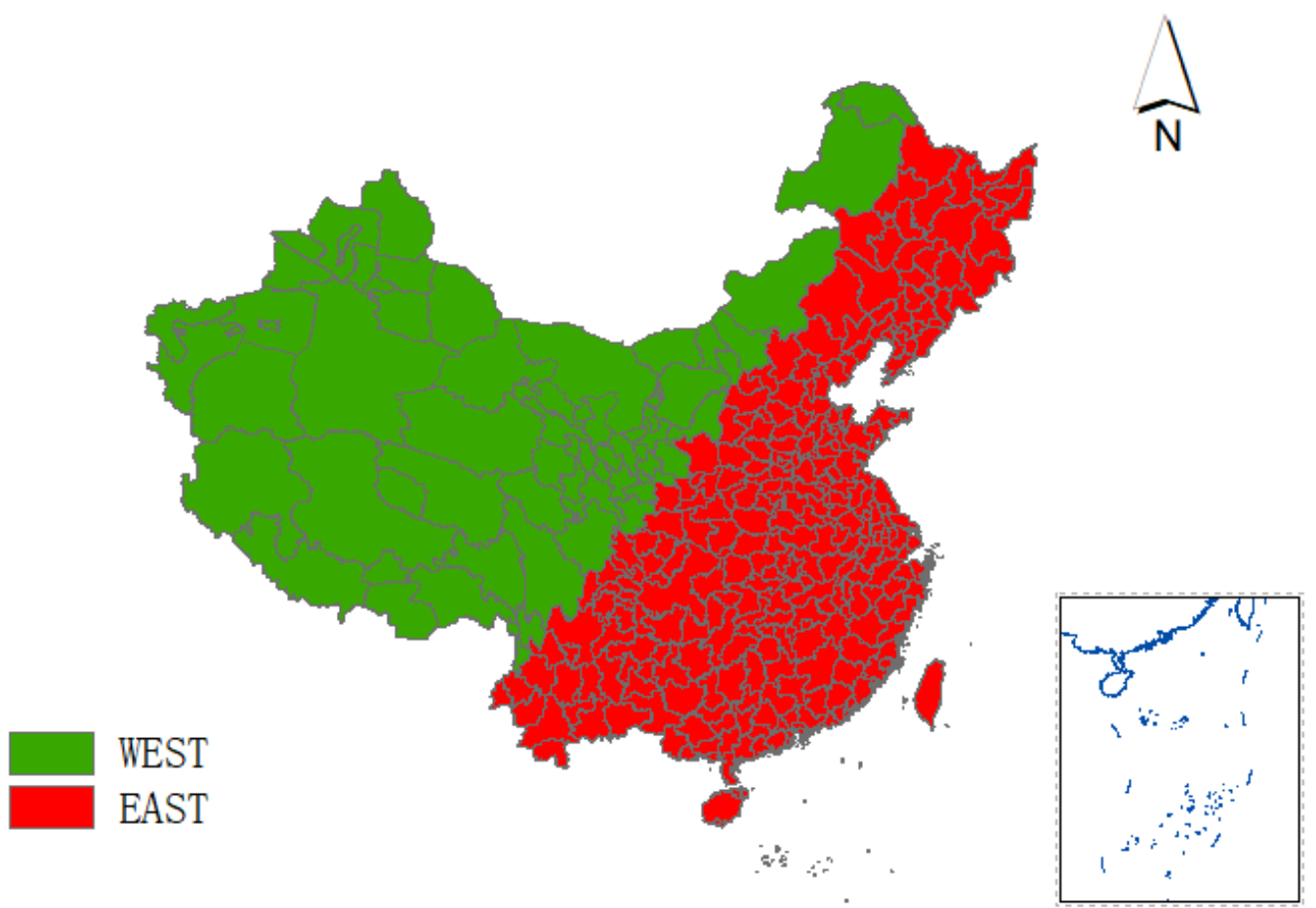

475

476

477

Fig.5 The results of the Hu Line division in China

Table 4 Regional heterogeneity test results

\begin{tabular}{c|cc|cc}
\hline \multirow{2}{*}{ variable } & \multicolumn{2}{|c|}{ lnpm } & \multicolumn{2}{c}{ lnurb } \\
\cline { 2 - 5 } & Right of the Hu Line & Left of the Hu Line & Right of the Hu Line & Left of the Hu Line \\
\hline \multirow{2}{*}{ lnpm } & & & $-1.624^{* * *}$ & $-0.397^{* *}$ \\
& & & $(-19.57)$ & $(-2.14)$ \\
lnurb & $0.292^{* * * *}$ & $-0.111^{* * *}$ & & \\
& $(9.78)$ & $(-3.30)$ & & \\
lnurb2 & $-0.093^{* * *}$ & 0.001 & & 0.219 \\
& $(-13.05)$ & $(0.09)$ & $1.051^{* * *}$ & $(0.99)$ \\
$\left.W^{*} \ln \right)$ & $0.716^{* * *}$ & $0.956^{* * *}$ & $(14.17)$ & $0.571^{* * *}$ \\
$W^{*} \ln u r b$ & $(33.38)$ & $(22.63)$ & $0.118^{* * *}$ &
\end{tabular}




\begin{tabular}{|c|c|c|c|c|}
\hline & $(-9.95)$ & $(1.00)$ & $(3.87)$ & $(9.50)$ \\
\hline \multirow{2}{*}{$\ln s c$} & -0.020 & 0.061 & & \\
\hline & $(-0.84)$ & $(1.48)$ & & \\
\hline \multirow{2}{*}{ lnec } & & & $0.262 * * *$ & -0.002 \\
\hline & & & $(5.93)$ & $(-0.02)$ \\
\hline \multirow{2}{*}{ lngre } & $-0.020 * * *$ & $-0.029 * *$ & & \\
\hline & $(-3.32)$ & $(-2.19)$ & & \\
\hline \multirow{2}{*}{$\operatorname{lnfdi}$} & 0.006 & $0.026 * * *$ & $-0.215^{* * *}$ & $0.247 * * *$ \\
\hline & $(1.46)$ & $(2.73)$ & $(-9.04)$ & (7.69) \\
\hline \multirow{2}{*}{$\operatorname{lnfdi} 2$} & & & $0.017 * * *$ & $-0.025 * * *$ \\
\hline & & & $(7.32)$ & $(-4.68)$ \\
\hline \multirow{2}{*}{ Intra } & $0.154 * * *$ & $0.057 * * *$ & $0.157 * * *$ & $-0.065^{*}$ \\
\hline & (18.66) & (3.97) & $(8.04)$ & $(-1.71)$ \\
\hline \multirow{2}{*}{ lnecon } & & & $0.231 * * *$ & $0.157 * * *$ \\
\hline & & & (13.00) & $(3.45)$ \\
\hline \multirow{2}{*}{ Іпрори } & & & $0.474 * * *$ & $0.203^{* * *}$ \\
\hline & & & (15.25) & $(3.88)$ \\
\hline \multirow{2}{*}{ lnmar } & & & $0.206^{* * *}$ & 0.044 \\
\hline & & & (15.82) & $(1.56)$ \\
\hline \multirow{2}{*}{ prec } & $-1.926^{* * *}$ & $-9.938 * * *$ & & \\
\hline & $(-5.79)$ & $(-4.20)$ & & \\
\hline \multirow{2}{*}{ _cons } & $0.741^{* * *}$ & -0.024 & $-3.783 * * *$ & -1.021 \\
\hline & $(6.44)$ & $(-0.11)$ & $(-12.05)$ & $(-1.49)$ \\
\hline
\end{tabular}

$\mathrm{t}$ statistics in parentheses

$* \mathrm{p}<0.1, * * \mathrm{p}<0.05, * * * \mathrm{p}<0.01$

\subsubsection{Analysis results of haze pollution equation}

The relationship between urbanization and haze pollution to the right of the $\mathrm{Hu}$ Line is still an inverted U-shaped curve, and the inflection point is $4.81 \%$. However, in the area to the left of the $\mathrm{Hu}$ Line, only the first-order coefficient of urbanization is significantly negative; the second-order coefficient of urbanization is not significant. This result shows that urbanization can promote the alleviation of haze pollution in the area to the left of the $\mathrm{Hu}$ Line.

For haze pollution and urbanization spatial lag terms, the area to the right of the $\mathrm{Hu}$ Line is consistent with the result of the overall regression. However, the spatial lag term of urbanization ( $W^{*} \ln u r b$ ) to the left of the $\mathrm{Hu}$ Line is not significant. A possible reason is that the level of urbanization in the western region is low, and it is difficult to have an impact on the local area when the urbanization in the surrounding areas increases only slightly. In addition, the corresponding coefficient of FDI (lnfdi) in the western region of the $\mathrm{Hu}$ Line is positive at the significance level of $1 \%$, which indicates 
that FDI leads to haze pollution in the area to the left of the Hu Line. Therefore, although the pollution paradise hypothesis is not tenable throughout the whole country, it does seem tenable in the areas left of the Hu Line. A possible reason for this outcome is that it is difficult to restrict the environmental standards to attract foreign investment due to the low economic level of the region to the left of the Hu Line. Whether to the right or the left of the $\mathrm{Hu}$ Line, traffic (lntra) will increase haze pollution, and precipitation (prec) will alleviate haze pollution.

\subsubsection{Analysis results of urbanization equation}

Whether to the right or the left of the Hu Line, haze pollution (lnpm) hinders urbanization. However, the haze pollution in the western region of the $\mathrm{Hu}$ Line is weaker than that in the east. A possible reason is that the level of urbanization in the western region of the $\mathrm{Hu}$ Line is lower than that in the eastern region. At present, the main goal is to promote urbanization; thus, the impact of haze on these areas will be weak. However, the urbanization level in the eastern region is higher, and the environmental status is given more attention; therefore, the region is more sensitive to haze.

The spatial lag term to the right of the $\mathrm{Hu}$ Line is not different from the previous results. The spatial lag term of urbanization ( $\left.W^{*} \ln u r b\right)$ on the left side of the Hu Line is positive, which is not significantly different from the previous conclusion. However, the spatial lag term of haze pollution $\left(W^{*} \operatorname{lnpm}\right)$ on the left of the $\mathrm{Hu}$ Line is not significant. A possible reason is that the level of urbanization to the left of the Hu Line is relatively low. Even though the surrounding areas have a certain amount of haze pollution, the main goal of the whole area to the left of the Hu Line is to promote urbanization. For other control variables, the first term of FDI (Infdi) to the right of the $\mathrm{Hu}$ Line is negative, while the second term (Infdi2) is positive; thus, the level of urbanization first decreases and then increases with the increase of FDI. However, for the region to the west, the coefficient of the first term of FDI $(\ln f d i)$ is positive, while the coefficient of the second term (lnfdi2) is negative, which shows that the relationship between FDI and urbanization has an inverted U-shaped curve. A possible reason for this result is that the initial inflow of foreign capital is conducive to local urbanization. However, while the area to the left of the $\mathrm{Hu}$ Line has higher terrain, the infrastructure is relatively poor. Thus, it is difficult for foreign capital to flow into the local infrastructure field, which hinders the further development of cities and towns. Other variables, except for that of traffic condition (lntra), have no significant difference from the results of the previous analysis. For the area to the left of the Hu Line, traffic conditions (lntra) are a very weak impediment to urbanization. A possible reason is that the terrain to the west of the line is more dangerous, and there are many mountainous areas; thus, the construction of roads in this terrain needs high levels of capital 
investment. Once excessive capital is occupied, other available capital for promoting urbanization will be relatively reduced. In addition, the corresponding coefficient of population density (lnpopu) in the area to the west of the Hu Line is 0.203 , which is higher than other coefficients, which indicates that if we want to promote urbanization in the western area, the issue of how to increase the population in the western area is the key factor.

\section{Robustness test}

To test the robustness of the model, the inverse distance matrix and the economic distance matrix are used to regress with GS3SLS. The inverse distance matrix is the reciprocal of Euclidean distance between two regions. The economic distance matrix is the reciprocal of the absolute value of the difference between the average per capita GDP of the two regions. The test results are shown in Table 5. There is no significant difference between the results of the robustness test and the previous results. Therefore, the model has good robustness.

Table 5 Robustness test results

\begin{tabular}{|c|c|c|c|c|}
\hline \multirow[b]{2}{*}{ variable } & \multicolumn{2}{|c|}{$\operatorname{lnpm}$} & \multicolumn{2}{|c|}{ lnurb } \\
\hline & $\begin{array}{c}\text { Inverse distance } \\
\text { matrix }\end{array}$ & $\begin{array}{c}\text { Economic distance } \\
\text { matrix }\end{array}$ & $\begin{array}{l}\text { Inverse distance } \\
\text { matrix }\end{array}$ & $\begin{array}{c}\text { Economic distance } \\
\text { matrix }\end{array}$ \\
\hline $\operatorname{lnpm}$ & & & $\begin{array}{c}-0.856 * * * \\
(-12.00)\end{array}$ & $\begin{array}{c}-1.060 * * * \\
(-17.58)\end{array}$ \\
\hline lnurb & $\begin{array}{c}0.256^{* * * *} \\
(12.59)\end{array}$ & $\begin{array}{c}0.266^{* * * *} \\
(10.69)\end{array}$ & & \\
\hline lnurb2 & $\begin{array}{c}-0.059 * * * \\
(-12.88)\end{array}$ & $\begin{array}{c}-0.079 * * * \\
(-13.34)\end{array}$ & & \\
\hline$W^{*} \operatorname{lnpm}$ & $\begin{array}{c}0.921 * * * \\
(44.32)\end{array}$ & $\begin{array}{c}0.618 * * * \\
(24.45)\end{array}$ & $\begin{array}{c}0.606 * * * \\
(7.69)\end{array}$ & $\begin{array}{c}0.801 * * * \\
(13.32)\end{array}$ \\
\hline$W^{*} \ln u r b$ & $\begin{array}{c}-0.295 * * * \\
(-16.43)\end{array}$ & $\begin{array}{c}-0.142 * * * \\
(-9.51)\end{array}$ & $\begin{array}{c}0.366^{* * * *} \\
(10.56)\end{array}$ & $\begin{array}{l}-0.027 \\
(-1.06)\end{array}$ \\
\hline $\ln s c$ & $\begin{array}{c}-0.072 * * * \\
(-3.52)\end{array}$ & $\begin{array}{c}-0.073^{* * *} \\
(-3.10)\end{array}$ & & \\
\hline lnec & & & $\begin{array}{c}0.120 * * * \\
(3.12)\end{array}$ & $\begin{array}{c}0.195 * * * \\
(4.95)\end{array}$ \\
\hline lngre & $\begin{array}{c}-0.035^{* * *} \\
(-6.37)\end{array}$ & $\begin{array}{c}-0.045^{* * *} \\
(-7.15)\end{array}$ & & \\
\hline $\ln f d i$ & $\begin{array}{l}0.002 \\
(0.67)\end{array}$ & $\begin{array}{c}-0.014 * * * \\
(-3.35)\end{array}$ & $\begin{array}{c}-0.092 * * * \\
(-5.22)\end{array}$ & $\begin{array}{c}-0.059 * * * \\
(-3.16)\end{array}$ \\
\hline $\ln f d i 2$ & & & $\begin{array}{c}0.007 * * * \\
(3.79)\end{array}$ & $\begin{array}{c}0.005^{* *} \\
(2.38)\end{array}$ \\
\hline lntra & $\begin{array}{c}0.137 * * * \\
(20.06)\end{array}$ & $\begin{array}{c}0.162 * * * \\
(19.70)\end{array}$ & $\begin{array}{l}0.009 \\
(0.54)\end{array}$ & $\begin{array}{c}0.055^{* * * *} \\
(3.20)\end{array}$ \\
\hline
\end{tabular}


prec

$$
-3.123 * * *
$$

$-3.834 * * *$

$0.480 * * *$

_cons

(4.64)
(-11.59)

$1.500 * * *$

(12.12)
$-2.775^{* * * *}$

$-3.595 * * *$

$\mathrm{t}$ statistics in parentheses

$* \mathrm{p}<0.1, * * \mathrm{p}<0.05, * * * \mathrm{p}<0.01$

\section{Conclusions and policy recommendations}

Based on panel data from 287 prefecture-level cities in China from 2000 to 2017, this paper studies the spatial interaction between haze pollution and urbanization. It is hoped that this study can supplement the relevant theories and provide a reference for improving atmospheric conditions and promoting the development of new urbanization.

The results show the following:

(1) Haze pollution and urbanization can influence each other. As a whole, haze pollution and urbanization have a typical inverted U-shaped relationship. Without considering the spatial factors, the turning point is the urbanization rate of $11.35 \%$. When considering the spatial factors, the inflection point becomes $6.22 \%$.

(2) Regional heterogeneity analysis shows that on the right of the Hu Line, haze and urbanization conform to the Environmental Kuznets curve. However, on the left of the $\mathrm{Hu}$ Line, haze pollution decreases with the improvement of urbanization level.

(3) In addition to haze pollution, urbanization also has a "spatial spillover effect". Haze in the surrounding areas will promote the urbanization level of the local area, but it will also make haze pollution in the local area more serious. When the level of urbanization in the surrounding areas increases, it will promote the level of urbanization in the local area and alleviate the haze pollution in the local area.

(4) Tertiary industry, greening, FDI and precipitation can help alleviate haze pollution, and traffic will aggravate haze pollution. Second, industry involvement, transportation, population density, economic level and market scale can promote regional urbanization. Urbanization first decreases with increasing FDI and then increases, and the inflection point is 518.01 yuan per capita FDI.

Based on the above conclusions, this paper puts forward the following policy recommendations:

(1) The relationship between haze pollution and urbanization has an inverted Ushaped curve. Therefore, when dealing with haze pollution, we should formulate haze 
control policies according to the urbanization level of the region and the surrounding areas to minimize the delay of urbanization while controlling haze. At the same time, they all have a spatial spillover effect. Therefore, in the governance of haze pollution and the promotion of urbanization, the cooperation between regions in formulating haze control policies and urbanization policies can achieve maximum benefits.

(2) In the area to the left of the Hu Line, the improvement of urbanization level is conducive to alleviating haze pollution, and the reduction of haze pollution can promote urbanization. Therefore, vigorously promoting the urbanization level in the area to the left of the $\mathrm{Hu}$ Line can realize a positive feedback effect between alleviating haze pollution and promoting urbanization.

(3) In areas with heavy haze pollution, we should promote the transformation of industrial structure, vigorously develop tertiary industry, and at the same time formulate policies to attract foreign investment to increase the green construction of cities and towns. In addition, in some seasons or areas with less precipitation, the prevention and control measures of haze should be stricter. In relatively less-developed areas, we should properly develop secondary industry sectors and increase employment, infrastructure investment and road construction. FDI and urbanization have a positive U-shaped relationship; therefore, we should formulate a policy of introducing foreign capital according to the current situation of regional FDI so that foreign capital can promote regional urbanization to the maximum extent.

\section{Acknowledgments}

This work was supported by the National Social Science Fund of China (Grant No. 18BGL275).

\section{Declarations}

- Authors' contributions

HCY: data curation, formal analysis, writing - original draft, writing - review \& editing.
HW: data curation, formal analysis.

WL: project administration, funding acquisition, conceptualization, supervision.

\section{- Funding}

This work was supported by the National Social Science Fund of China (Grant No. 18BGL275).

- Competing interests

The authors declare that they have no competing interests.

- Availability of data and material

The datasets generated and analyzed during the current study are not publicly available due to relative requirements of financially supporting projects but are available from the corresponding author on reasonable request basis. 
All authors read and approved the final manuscript.

\section{References}

Bai, L., He, Z., Li, C., \& Chen, Z. (2020). Investigation of yearly indoor/outdoor PM2.5 levels in the perspectives of health impacts and air pollution control: Case study in Changchun, in the northeast of China. Sustainable Cities and Society, 101871. http://doi.org/https://doi.org/10.1016/j.scs.2019.101871

Bai, X., Chen, J., \& Shi, P. (2012). Landscape Urbanization and Economic Growth in China: Positive Feedbacks and Sustainability Dilemmas. Environmental Science \& Technology, 46(1), 132-139. http://doi.org/10.1021/es202329f

Cai, Y., \& Lv, J. (2018). Research on Evaluation of regional development quality of Beijing Tianjin Hebei region based on entropy method. Journal of Industrial Technological Economics, 37(11), 67-74.

Cao, Z., Wu, Z., Kuang, Y., \& Huang, N. (2015). Correction and application of DMSP / OLS night light image in China. Journal of Geo-information Science, 17(09), 1092-1102.

Chai, Z., Wang, S., \& Qiao, J. (2015). Estimation of town level GDP in Pearl River Delta Based on night light data. Tropical Geography, 35(03), 379-385.

Chen, L., Shi, M., Gao, S., Li, S., Mao, J., Zhang, H., Sun, Y., Bai, Z., \& Wang, Z. (2017). Assessment of population exposure to PM2.5 for mortality in China and its public health benefit based on BenMAP. Environmental Pollution, 221, 311-317. http://doi.org/10.1016/j.envpol.2016.11.080

de Arruda Moreira, G., Da Silva Andrade, I., Cacheffo, A., Da Silva Lopes, F. J., Calzavara Yoshida, A., Gomes, A. A., Da Silva, J. J., \& Landulfo, E. (2021). Influence of a Biomass-Burning Event in PM2.5 Concentration and Air Quality: A Case Study in the Metropolitan Area of Sao Paulo. Sensors, 21(4252) http://doi.org/10.3390/s21020425

Dong, Q., Lin, Y., Huang, J., \& Chen, Z. (2020). Has urbanization accelerated PM2.5 emissions? An empirical analysis with cross-country data. China Economic Review, 59, 101381. http://doi.org/https://doi.org/10.1016/j.chieco.2019.101381

Du, Y., Sun, T., Peng, J., Fang, K., Liu, Y., Yang, Y., \& Wang, Y. (2018). Direct and spillover effects of urbanization on PM2.5 concentrations in China's top three urban agglomerations. Journal of Cleaner Production, 190, 72-83. http://doi.org/10.1016/j.jclepro.2018.03.290

Du, Y., Wan, Q., Liu, H., Liu, H., Kapsar, K., \& Peng, J. (2019). How does urbanization influence PM2.5 concentrations? Perspective of spillover effect of multi-dimensional urbanization impact. Journal of Cleaner Production, 220, 974-983. http://doi.org/10.1016/j.jclepro.2019.02.222

Fang, C., Liu, H., Li, G., Sun, D., \& Miao, Z. (2015). Estimating the Impact of Urbanization on Air Quality in China Using Spatial Regression Models. Sustainability, 7(11), 15570-15592. http://doi.org/10.3390/su71115570

Fu, X., Li, L., Lei, Y., Wu, S., Yan, D., Luo, X., \& Luo, H. (2020). The economic loss of health effect damages from PM2.5 pollution in the Central Plains Urban Agglomeration. Environmental science and pollution research international http://doi.org/10.1007/s11356-020-08560-3

Gan, T., Yang, H., \& Liang, W. (2021). How do urban haze pollution and economic development affect each other? Empirical evidence from 287 Chinese cities during 2000-2016. Sustainable Cities and Society, 65(102642) http://doi.org/10.1016/j.scs.2020.102642

Han, L., Zhou, W., Li, W., \& Li, L. (2014). Impact of urbanization level on urban air quality: A case of 
fine particles (PM2.5) in Chinese cities. Environmental Pollution, 194, 163-170. http://doi.org/10.1016/j.envpol.2014.07.022

Jiang, P., Yang, J., Huang, C., \& Liu, H. (2018). The contribution of socioeconomic factors to PM2.5 pollution in urban China. Environmental Pollution, 233, 977-985. http://doi.org/https://doi.org/10.1016/j.envpol.2017.09.090

Kliengchuay, W., Worakhunpiset, S., Limpanont, Y., Meeyai, A. C., \& Tantrakarnapa, K. (2021). Influence of the meteorological conditions and some pollutants on PM10 concentrations in Lamphun, Thailand. Journal of Environmental Health Science and Engineering http://doi.org/10.1007/s40201-020-00598-2

Li, H., Zhou, D., \& Wei, Y. (2018). An Assessment of PM2.5-Related Health Risks and Associated Economic Losses in Chinese Cities. Huan jing ke xue= Huanjing kexue, 39(8) http://doi.org/10.13227/j.hjkx.201711237

Li, M., \& Zhang, Y. (2019). The migration effect of air pollution -- a study based on the choice of university cities for international students in China. Economic Research Journal, 54(06), 168-182.

Li, X., \& Zhang, X. (2011). Study on land ecological security in the process of urbanization based on entropy weight method. Journal of Arid Land Resources and Environment, 25(09), 13-17.

Liang, L., Bian, J., Li, A., Feng, W., Lei, G., Zhang, Z., \& Zuo, J. (2020). Radiation consistency correction of DMSP / OLS and NPP / viirs luminous data in China Pakistan Economic Corridor. Journal of Remote Sensing, 24(02), 149-160.

Lin, W., Wu, M., Zhang, Y., Zeng, R., Zheng, X., Shao, L., Zhao, L., Li, S., \& Tang, Y. (2018). Regional differences of urbanization in China and its driving factors. Science China-Earth Sciences, 61(6), 778-791. http://doi.org/10.1007/s11430-016-9163-3

Liu, J., Yan, G., Wu, Y., Wang, Y., Zhang, Z., \& Zhang, M. (2018). Wetlands with greater degree of urbanization improve PM2.5 removal efficiency. Chemosphere, 207, 601-611. http://doi.org/10.1016/j.chemosphere.2018.05.131

Liu, Q., Wang, S., Zhang, W., Li, J., \& Dong, G. (2019). The effect of natural and anthropogenic factors on PM2.5: Empirical evidence from Chinese cities with different income levels. Science of the Total Environment, 653, 157-167. http://doi.org/10.1016/j.scitotenv.2018.10.367

Liu, X., Sun, T., \& Feng, Q. (2020). Dynamic spatial spillover effect of urbanization on environmental pollution in China considering the inertia characteristics of environmental pollution. Sustainable Cities and Society, 53(101903) http://doi.org/10.1016/j.scs.2019.101903

Liu, Z., He, C., Zhang, Q., Huang, Q., \& Yang, Y. (2012). Extracting the dynamics of urban expansion in China using DMSP-OLS nighttime light data from 1992 to 2008. Landscape and Urban Planning, 106(1), 62-72. http://doi.org/10.1016/j.landurbplan.2012.02.013

Lu, D., Xu, J., Yang, D., \& Zhao, J. (2017). Spatio-temporal variation and influence factors of PM2.5 concentrations in China from 1998 to 2014. Atmospheric Pollution Research, 8(6), 1151-1159. http://doi.org/10.1016/j.apr.2017.05.005

$\mathrm{Lu}, \mathrm{J} ., \mathrm{Li}, \mathrm{B} .$, \& Li, H. (2019). The influence of land finance and public service supply on periurbanization: Evidence from the counties in China. Habitat International, 92(UNSP 102039) http://doi.org/10.1016/j.habitatint.2019.102039

Maji, K. J., Ye, W., Arora, M., \& Nagendra, S. M. S. (2018). PM2.5-related health and economic loss assessment for 338 Chinese cities. Environment International, 121(1), 392-403. http://doi.org/10.1016/j.envint.2018.09.024 
Qin, H., Hong, B., Huang, B., Cui, X., \& Zhang, T. (2020). How dynamic growth of avenue trees affects particulate matter dispersion: CFD simulations in street canyons. Sustainable Cities and Society, 61, 102331. http://doi.org/https://doi.org/10.1016/j.scs.2020.102331

Shen, H., Tao, S., Chen, Y., Ciais, P., Guneralp, B., Ru, M., Zhong, Q., Yun, X., Zhu, X., Huang, T., Tao, W., Chen, Y., Li, B., Wang, X., Liu, W., Liu, J., \& Zhao, S. (2017). Urbanization-induced population migration has reduced ambient PM2.5 concentrations in China. Science Advances, 3(e17003007) http://doi.org/10.1126/sciadv.1700300

Shi, H., Wang, S., \& Guo, S. (2019). Predicting the impacts of psychological factors and policy factors on individual's PM2.5 reduction behavior: An empirical study in China. Journal of Cleaner Production, 241(UNSP 118416) http://doi.org/10.1016/j.jclepro.2019.118416

Tian, G., \& Wu, J. (2015). Comparing urbanization patterns in Guangzhou of China and Phoenix of the USA: The influences of roads and rivers. Ecological Indicators, 52, 23-30. http://doi.org/10.1016/j.ecolind.2014.11.024

Wang, F., Mao, A., Li, H., \& Jia, M. (2013). Measurement of urbanization quality and analysis of spatial differences in Shandong Province Based on entropy method. Scientia Geographica Sinica, 33(11), 1323-1329.

Wang, N., Zhu, H., Guo, Y., \& Peng, C. (2018). The heterogeneous effect of democracy, political globalization, and urbanization on PM2.5 concentrations in G20 countries: Evidence from panel quantile regression. Journal of Cleaner Production, 194, 54-68. http://doi.org/10.1016/j.jclepro.2018.05.092

Wang, S. (2013). Types and selection of weight matrix in spatial econometric model. Journal of Quantitative Economics, 30(03), 57-63.

Wang, S., Gao, S., Li, S., \& Feng, K. (2020). Strategizing the relation between urbanization and air pollution: Empirical evidence from global countries. Journal of Cleaner Production, 243(UNSP 118615) http://doi.org/10.1016/j.jclepro.2019.118615

Wang, X., Tian, G., Yang, D., Zhang, W., Lu, D., \& Liu, Z. (2018). Responses of PM2.5 pollution to urbanization in China. Energy Policy, 123, 602-610. http://doi.org/10.1016/j.enpol.2018.09.001

Wu, H., Gai, Z., Guo, Y., Li, Y., Hao, Y., \& Lu, Z. (2020). Does environmental pollution inhibit urbanization in China? A new perspective through residents' medical and health costs. Environmental Research, 182(109128) http://doi.org/10.1016/j.envres.2020.109128

Wu, J., Zheng, H., Zhe, F., Xie, W., \& Song, J. (2018). Study on the relationship between urbanization and fine particulate matter (PM2.5) concentration and its implication in China. Journal of Cleaner Production, 182, 872-882. http://doi.org/10.1016/j.jclepro.2018.02.060

Xie, W., Deng, H., \& Chong, Z. (2019). The Spatial and Heterogeneity Impacts of Population Urbanization on Fine Particulate (PM2.5) in the Yangtze River Economic Belt, China. International Journal of Environmental Research and Public Health, 16(10586) http://doi.org/10.3390/ijerph16061058

Xie, Y., Dai, H., Zhang, Y., Wu, Y., Hanaoka, T., \& Masui, T. (2019). Comparison of health and economic impacts of PM2.5 and ozone pollution in China. Environment International, 130, 104881. http://doi.org/https://doi.org/10.1016/j.envint.2019.05.075

Xu, D., \& Hou, G. (2019). The Spatiotemporal Coupling Characteristics of Regional Urbanization and Its Influencing Factors: Taking the Yangtze River Delta as an Example. Sustainability, 11(8223) http://doi.org/10.3390/su11030822 
Xu, S., Miao, Y., Gao, C., Long, R., Chen, H., Zhao, B., \& Wang, S. (2019). Regional differences in impacts of economic growth and urbanization on air pollutants in China based on provincial panel estimation. Journal of Cleaner Production, 208, 340-352. http://doi.org/10.1016/j.jclepro.2018.10.114

Yang, D., Wang, X., Xu, J., Xu, C., Lu, D., Ye, C., Wang, Z., \& Bai, L. (2018). Quantifying the influence of natural and socioeconomic factors and their interactive impact on PM2.5 pollution in China. Environmental Pollution, 241, 475-483. http://doi.org/10.1016/j.envpol.2018.05.043

Yang, Q., Yuan, Q., Li, T., Shen, H., \& Zhang, L. (2017). The Relationships between PM2.5 and Meteorological Factors in China: Seasonal and Regional Variations. International Journal of Environmental Research and Public Health, 14(151012) http://doi.org/10.3390/ijerph14121510

Ye, C., Sun, C., \& Chen, L. (2018). New evidence for the impact of financial agglomeration on urbanization from a spatial econometrics analysis. Journal of Cleaner Production, 200, 65-73. http://doi.org/10.1016/j.jclepro.2018.07.253

Zeng, H., \& Shen, J. (2019). Spatial correlation analysis of provincial FDI and haze pollution. Jiangxi Social Sciences, 39(10), 50-60.

Zhang, Y., Shuai, C., Bian, J., Chen, X., Wu, Y., \& Shen, L. (2019). Socioeconomic factors of PM2.5 concentrations in 152 Chinese cities: Decomposition analysis using LMDI. Journal of Cleaner Production, 218, 96-107. http://doi.org/https://doi.org/10.1016/j.jclepro.2019.01.322

Zhao, H., Guo, S., \& Zhao, H. (2018). Characterizing the Influences of Economic Development, Energy Consumption, Urbanization, Industrialization, and Vehicles Amount on PM2.5 Concentrations of China. Sustainability, 10(25747) http://doi.org/10.3390/su10072574

Zhao, X., Zhou, W., Han, L., \& Locke, D. (2019). Spatiotemporal variation in PM2.5 concentrations and their relationship with socioeconomic factors in China's major cities. Environment International, 133(UNSP 105145A) http://doi.org/10.1016/j.envint.2019.105145

Zhou, J., Xia, N., \& Liang, W. (2019). Foreign investment, independent innovation and haze pollution: evidence from China. $R \& D$ Management, 31(02), 78-90.

Zhou, T., Zhao, R., \& Zhou, Y. (2017). Factors Influencing Land Development and Redevelopment during China's Rapid Urbanization: Evidence from Haikou City, 2003-2016. Sustainability, 9(201111) http://doi.org/10.3390/su9112011

Zhu, G., Hu, W., Liu, Y., Cao, J., Ma, Z., Deng, Y., Sabel, C. E., \& Wang, H. (2019). Health burdens of ambient PM2.5 pollution across Chinese cities during 2006 - 2015. Journal of Environmental Management, 243, 250-256. http://doi.org/https://doi.org/10.1016/j.jenvman.2019.04.119

Zhu, W., Wang, M., \& Zhang, B. (2019). The effects of urbanization on PM2.5 concentrations in China's Yangtze River Economic Belt: New evidence from spatial econometric analysis. Journal of Cleaner Production, 239(UNSP 118065) http://doi.org/10.1016/j.jclepro.2019.118065 